\title{
REVIEW
}

\section{Year in review 2012: Critical Care - out-of-hospital cardiac arrest and trauma}

\author{
Scott A Goldberg*, Auna Leatham and Paul E Pepe
}

\begin{abstract}
In 2012 Critical Care published many articles pertaining to the resuscitation of out-of-hospital cardiac arrest and trauma. In this review, we summarize several of these articles, including those regarding advances in resuscitation techniques and methods. We examine articles pertaining to prehospital endotracheal intubation, the use of specialized devices for cardiopulmonary resuscitation and policies regarding transport destinations for both cardiac arrest and trauma patients. Articles on the predictors of outcome in both pediatric and adult populations are evaluated, including articles on the effects of obesity on survival from hemorrhage and pediatric outcomes from traumatic cardiac arrest. The effects of the type and volume of resuscitation fluids for both adult and pediatric patients are discussed, as are the factors contributing to hypothermia in trauma patients.
\end{abstract}

\section{Introduction}

Many articles pertaining to resuscitation for out-ofhospital cardiac arrest (OHCA) and trauma were published in 2012. Several articles featured in Critical Care addressed various aspects of the prehospital and emergency department (ED) management of OHCA, including success rates for endotracheal intubation (ETI), the use of specialized devices and hospital destination policies. Likewise, the management of traumatic injuries was examined in articles evaluating the mode of transport for trauma, outcome predictors and the effects of volume resuscitation in adult and pediatric trauma populations. The articles also evaluated pediatric survival from traumatic cardiac arrest, the effects of obesity on survival and various factors related to the development of post-traumatic hypothermia. In this discussion, we

\footnotetext{
* Correspondence: scott.goldberg@utsouthwestern.edu Department of Surgery, Division of Emergency Medicine, University of Texas, Southwestern Medical Center at Dallas, 5323 Harry Hines Blvd, Box 8890, Dallas, TX 75390, USA
}

review and annotate the findings of these studies that contributed to our evolving understanding of OHCA and trauma resuscitation in 2012 .

\section{Success rate of field endotracheal intubation depends on provider type}

Previous studies have confirmed that ETI can prevent hypoxia and diminish the mortality rates in resuscitated patients with airway compromise [1,2]. Nevertheless, incorrectly performed ETI carries high morbidity [3]. The failure rates for ETI placement by nonphysician providers may be as much as $15 \%$ higher $[4,5]$ than the failure rates documented for physicians in the prehospital and hospital settings [6]. Among several related factors, one explanation for this discrepancy may be the greater availability and use of rapid sequence induction (RSI) intubation techniques by physicians. The use of RSI can facilitate ETI and thus may decrease the adverse outcomes associated with difficult airway management [7].

In a 2012 article in Critical Care, Lossius and colleagues completed a meta-analysis to review physician versus nonphysician ETI success rates in the prehospital setting [8]. Data were extracted from 33 original studies comparing success rate by type of provider with respect to the availability of RSI medications, analgesics or anesthetics. The analysis revealed that the median ETI success rates for all intubation attempts were significantly higher for physicians $(99 \%, 95 \% \mathrm{CI}=97$ to $100 \%)$ than nonphysicians ( $85 \%, 95 \% \mathrm{CI}=49$ to $99 \%)$. Nonphysician ETI was improved with RSI, with a median success rate of $97 \%$ for RSI versus $68 \%$ with no drug use and $81 \%$ with analgesia only. When comparing physician with nonphysician ETI success rates in the setting of RSI drug use only, there was a significant positive outcome with physician-performed procedures $(99 \%$ vs. $96 \%, P<0.05)$ [8]. This study also suggests that this benefit of RSI exists in prehospital care as well as in the ED setting regardless of provider type.

Although it appears on the surface that physician performance of ETI both with and without RSI was 
superior, there are other factors to consider. For example, the physician cohort may be a group that routinely performs RSI, as compared with nonphysicians who do not perform this skill as frequently. Infrequent performance can be confounded by variables such as deployment strategies for the prehospital care system and the type of initial training provided to those performing the ETI $[9,10]$. Success rates for nonphysicians can be exceptionally high, but only according to the nature of the emergency medical services (EMS) system and other factors such as initial training and intensive medical director oversight of the providers [9]. However, for the typical EMS system in which many of the frequency and oversight issues are less optimal, airway management in the prehospital arena remains a controversial topic, with the optimal management algorithm yet to be clarified. The higher failure rate among nonphysicians demonstrated in Lossius and colleagues' study suggests that alternative ventilatory and backup airway techniques might be more appropriate, although further prospective research is necessary before practice changes can be implemented.

\section{Specialized devices for resuscitation in out-of-hospital cardiac arrest \\ Comparison of monophasic and biphasic defibrillators in a pediatric population}

Standard resuscitation algorithms recommend defibrillation attempts for the management of unstable ventricular tachycardia (VT) or ventricular fibrillation (VF) in children [11,12]. However, data are lacking in terms of how best to deliver the defibrillation current in the pediatric population. Previous studies have demonstrated the utility of biphasic defibrillators in adult OHCA [13-19], but complementary data for the pediatric population remain limited. A 2012 study published by Tanabe and colleagues in Critical Care was therefore an important contribution, in that the researchers specifically evaluated the outcomes of pediatric OHCA patients who received defibrillation attempts with either monophasic or biphasic defibrillators [20].

Using the prospectively collected information secured in a nationwide Utstein-style registry of all OHCA patients in Japan, the investigators sought to identify the outcomes of pediatric patients ( 1 to 17 years of age) who were defibrillated between 2005 and 2009. A unique aspect of this study was that all EMS providers in this system use only epinephrine and defibrillation as therapies for OHCA. Also, defibrillators are used in the automated external defibrillation mode and they deliver standard adult doses of electricity with pediatric attenuation pads for children, ages 1 through 8 . The primary outcome was 1-month survival with good neurologic outcome as defined by cerebral performance category (CPC) score of 1 or 2.

Of a total 5,628 pediatric OHCA patients enrolled during the multiyear study period, 430 receiving defibrillation attempts for VF or VT were included for analysis 303 (70\%) with biphasic attempts and 127 (30\%) with monophasic attempts. The overall rate of return of spontaneous circulation before hospital arrival for those receiving biphasic defibrillation attempts was $27.4 \%$ versus $24.4 \%$ for those receiving monophasic attempts (not significant). Survival rates at 1 month were $32.3 \%$ and $35.6 \%$. Of 303 patients receiving biphasic defibrillation, 74 (24.4\%) survived with good neurologic outcomes at 1 month. This is in contrast to 22 of 127 patients (17.5\%) receiving monophasic defibrillation attempts. However, despite the superficial trend in improved neurological outcomes, none of these primary outcome measures could be demonstrated to be statistically significant.

These results mirror previous adult literature showing no difference in long-term outcomes between monophasic and biphasic defibrillation for OHCA. Nevertheless, as is the case in such investigations, particularly those involving the pediatric OHCA population, a major limitation of the study was a lack of statistical power given the limited number of subjects. Also, the data evaluated did not directly address the termination of the ventricular arrhythmia by the defibrillation attempts. As such, this study did not definitively demonstrate which type of defibrillator was more effective at terminating the arrhythmia nor did it demonstrate any difference in outcome. However, this lack of significant difference may simply be due to a type II statistical error and such a comparison should be reconsidered in future studies. Nevertheless, as the first study of its kind, this study confirms the efficacy of biphasic defibrillation in the resuscitation of pediatric patients with OHCA due to VF or VT.

\section{Use of a load distributing band compression device for out-of-hospital cardiac arrest after hospital arrival}

In another article appearing in Critical Care in 2012, Hock Ong and colleagues investigated a load-distributing band (LDB) device as a substitute for manual chest compressions [21]. There is a substantial amount of literature demonstrating improved survival with improved quality of chest compressions, including higher compression fractions [22], markedly limited hands-off time [23,24] and maintenance of a recommended rate of 100 to $120 \mathrm{com}$ pressions/minute [25,26]. The LDB device was developed in an attempt to provide a more evenly distributed force over the entire chest as well as improved compressive forces and a consistent compression rate and depth while also decreasing provider fatigue. Despite these theoretical 
benefits, previous studies of LDB devices have had conflicting results $[27,28]$. Although these previous studies have investigated the use of LDB devices for OHCA in the out-of-hospital setting, they have not specifically examined their use after arrival in the ED.

Hock Ong and colleagues evaluated the use of the AutoPulse $^{\mathrm{mm}}$ LDB device (Revivant Corporation, Sunnyvale, CA, USA) in patients with nontraumatic OHCA transported to two EDs in Singapore [21]. The primary endpoint was survival to hospital discharge and analysis was intention to treat. The study population also included those cases of cardiac arrest that occurred after arrival in the ED. This EMS system does not allow for termination of resuscitation in the field and therefore all OHCA patients were transported to hospital. Prior to 2007, the standard of care was manual chest compressions for patients treated in the ED. The change to LDB compressions occurred in 2007. A before and after comparison was made and a total of 1,011 patients were enrolled, with 459 patients in the manual compression phase and 552 patients in the LDB compression phase. During the LDB phase, a majority (82\%) of the patients had the LDB device applied.

The authors found a significant advantage for the LDB cohort in terms of survival to discharge (odds ratio $(\mathrm{OR})=2.55,95 \% \mathrm{CI}=1.00$ to 6.47 ), survival to admission $(\mathrm{OR}=1.49,95 \% \mathrm{CI}=1.07$ to 2.09$)$ and $\mathrm{CPC}$ at discharge ( $\mathrm{OR}=8.7,95 \%$ CI 1.1 to 71.6 for CPC 1 or 2). However, there was a significantly lower frequency of VF and VT cases among patients in the manual compression group. Because VF and VT presentations are associated with better outcomes [29], this may have contributed to the increased survival rates in the LDB group. This may also indicate improvements in the systems of care or other factors that changed between study phases, typical concerns when historical controls are employed. The blending of prehospital and ED cases also creates methodological issues. Another confounding concern is that the study was funded by the device manufacturer and the lead author holds patents filed for this technology.

While this study has methodological flaws, the findings may also indicate that this is a way to improve outcomes, especially if the quality of cardiopulmonary resuscitation (CPR) performed in the ED is less than optimal. Prior studies in the out-of-hospital setting employing this device have indicated improvement in outcomes when manual CPR is suboptimal but no significant difference with high-quality manual CPR. In those studies, chest compressions were most often performed in systems with firefighter crews who are comprised of very strong personnel capable of robust compressions as well as enough depth of staffing that they can routinely take turns to avoid fatigue. It is not clear who was performing ED compressions in the current study. If less robust compressions with fewer substitute compressors were involved, the LDB could prove advantageous. In the end, the current evidence neither supports nor refutes the utility of LDB devices [30]. Once again, this study calls attention to a better understanding and better study design regarding LDB use for OHCA.

\section{Transport choices for out-of-hospital cardiac arrest and trauma \\ Consequences of choice of hospital in out-of-hospital cardiac arrest}

Depending on definitions, survival to hospital discharge after OHCA ranges from 1 to 31\% [31-34]. Studies have shown survival benefit with the use of induced hypothermia (IH) following OHCA [35,36] as well as percutaneous cardiac intervention (PCI) [37] or the combination of both [38]. Previous literature has also shown survival benefit after OHCA with admission to hospitals with PCI capabilities [39], but data are lacking in terms of independently evaluating the benefit of IH or PCI.

In a 2012 Critical Care article, Wnent and colleagues performed a retrospective analysis of destination hospital capabilities and interventions performed for patients who had OHCA [40]. Of 889 resuscitation attempts evaluated, $360(40.5 \%)$ achieved return of spontaneous circulation. Those patients were then categorized based on the PCI capability of the initial hospital admission and interventions including $\mathrm{IH}$ and $\mathrm{PCI}$, with a primary endpoint of discharge with good neurological outcome defined as CPC 1 or 2 [40].

The analysis demonstrated that patients who received PCI $(\mathrm{OR}=4.57,95 \% \mathrm{CI}=2.20$ to 9.50$)$ or $\mathrm{IH}(\mathrm{OR}=5.31$, $95 \% \mathrm{CI}=1.91$ to 14.77 ) had improved survival to hospital discharge. Interestingly, this survival benefit with good neurological outcome held for any patient admitted to a PCI-capable hospital regardless of any intervention $(\mathrm{OR}=3.14,95 \% \mathrm{CI}=1.51$ to 6.56$)$. However, overall compliance with $\mathrm{IH}$ and PCI guidelines in this cohort was not frequent.

While Wnent and colleagues demonstrated that PCI and $\mathrm{IH}$ protocols do improve outcomes, admission to a PCI-capable center actually improves outcomes independent of intervention. These interventions may therefore be surrogate variables for other factors, be they higher skills or resources in such centers, selection bias in terms of patients transported or some other sublime element. Although the reasons for this finding warrant further scrutiny, they also give EMS providers the opportunity to re-evaluate guidelines for choice of destination in OHCA.

\section{Helicopter transport to a trauma center to improve outcome after severe blunt trauma}

Access to a trauma center has been shown to reduce mortality for trauma patients [41], and many factors 
affect this access including the modality of transport [42]. Studies have also shown that trauma patients transported by helicopter can have greater survival compared with transport by ground, even despite longer transport times and more severe injuries [43-45].

Last year in Critical Care, Desmettre and colleagues sought to study the impact of mode of transport on mortality in blunt trauma patients transported directly from scene to a university hospital using secondary analysis of data from the multicenter French Intensive Care Research for Severe Trauma cohort study [46]. The authors evaluated data from 1,958 patients, $74 \%$ of whom were transported by ground and $26 \%$ by helicopter. All patients received prehospital care from a physician-led emergency response team. The primary endpoint was survival to discharge as determined through a multivariate analysis of 1,817 patients evaluated in terms of mode of transport and whether or not the patient died before discharge from the ICU during the first 30 days after injury.

The authors found that patients transported by helicopter had no reduction in crude mortality before hospital discharge. However, after adjustment for initial patient status, helicopter-transported patients showed a significant reduction in mortality $(\mathrm{OR}=0.68,95 \% \mathrm{CI}=$ 0.47 to $0.98, P<0.05)$ even after adjustment for injury severity. The helicopter-transported group did have increased time to admission and received more aggressive prehospital interventions, but the time to admission had no effect on mortality.

In conclusion, this study by Desmettre and colleagues demonstrates a survival benefit with helicopter transport for blunt trauma patients despite longer transport times. However, this benefit may rely at least in part on the aggressive administration of prehospital interventions by the air medical team, countering previous research suggesting prehospital intervention for trauma has no mortality benefit [47]. These results provide further support to the utility of using helicopter transport for critical trauma patients. They also prompt the need for further investigation into which subsets of patients may benefit most from this transport modality, as well as the effect of aggressive prehospital interventions in critically injured trauma patients.

\section{Hemorrhage and volume replacement in hypovolemic shock following trauma}

\section{Comparison of prediction tools for massive transfusion in} severe trauma

As many as one in four patients presenting to the ED after major trauma will have a unique coagulopathy [48]. Early activation of massive transfusion (MT) protocols with balanced ratios of blood products and coagulation factors has been shown to improve outcomes in patients with traumatic hemorrhage [49-51]. However, identification of those patients who will benefit from early transfusion remains a challenge.

Although early screening for the acute coagulopathy of trauma should be an important step in patient management [48], the results of standard coagulation profiles including the International Normalized Ratio and the activated partial thromboplastin time are often delayed or inaccurate [52]. Newer studies including rotational thromboelastometry [52] and rapid thromboelastography [53] show promise, but are costly and currently have limited availability. In a 2012 Critical Care article, Brockamp and colleagues compared six scoring systems for the identification of patients requiring MT in an attempt to better delineate those patients at the highest risk for requiring MT [54].

The authors utilized the multicenter prospective TraumaRegister $\mathrm{DGU}^{\circ}$ to identify all patients receiving $\geq 10$ units of packed red blood cells between ED presentation and arrival in the ICU. Patients were included only if records included all variables necessary to calculate six MT prediction scores and the patient survived to ICU admission. Of the total of 56,573 patients entered into the registry between 2002 and 2010, 5,147 (9\%) met the inclusion criteria. Of these patients, 95\% had experienced blunt trauma with an overall MT rate of $5.6 \%$.

The tools evaluated were the trauma-associated severe hemorrhage (TASH) score [55], the Prince of Wales Hospital/Rainer (PWH) score [56], the Vandromme score [57], the assessment of blood consumption score [58], the Schreiber score [59], and the Larson score [60].

The TASH score was found to have the highest accuracy (area under the curve $=0.889,95 \% \mathrm{CI}=0.871$ to 0.907), followed by the PWH score (area under the curve $=0.860,95 \% \mathrm{CI}=0.839$ to 0.881 ). The assessment of blood consumption had the lowest accuracy (area under the curve $=0.763,95 \% \mathrm{CI}=0.732$ to 0.794 ). The highest sensitivity for predicting MT was attained using the Schreiber score $(85.8 \%)$, but this score also had the lowest specificity (61.7\%). The TASH and PWH scores still had sensitivities of $84.4 \%$ and $80.6 \%$, respectively, but also had specificities of $78.4 \%$ and $77.7 \%$, respectively. The TASH score and the PWH were found to be significantly better than the other scores $(P=0.0413)$ in terms of predicting MT.

When examining these results, one must note that both the TASH and PWH scores, while having the best accuracy, are also the most complicated to use [55,56]. Both of the military derived scores (Schreiber and Larson) had reasonable sensitivity but they may not be applicable to a civilian cohort with $95 \%$ blunt trauma. Importantly, the best performing TASH score was initially derived and validated using the same registry data as the current study [55]. One should also note that $91 \%$ 
of the dataset was excluded, including all patients receiving hemostatic factors and antifibrinolytics.

Despite these limitations, this study by Brockamp and colleagues was an important exercise because it attempted to directly validate and compare multiple scoring systems for the prediction of patients requiring MT. Future studies might integrate rotational thromboelastometry, rapid thromboelastography and antifibrinolytics into prediction algorithms, with an ultimate goal of deriving a quick, simple and accurate method of determining which patients will benefit from early MT. However, all of the described scoring methods should be used with caution and resuscitative efforts should be tailored to each patient's mechanism of injury and physiologic needs until more accurate prediction tools are available.

\section{Impact of obesity on survival from trauma}

Obesity, defined as body mass index (BMI) $\geq 30$ [61], carries a higher risk of organ dysfunction, hospital stay and ICU days following trauma $[62,63]$. The direct relationship between obesity and mortality, however, is less clear [63-66]. Nelson and colleagues published a study in Critical Care in 2012 evaluating factors associated with the outcomes of obese trauma patients treated at a single Swiss trauma center from 1996 to 2009 [67]. Using a retrospective registry cohort, they identified 1,084 adult patients with Injury Severity Score $\geq 16$. The authors stratified this cohort into four groups: underweight (BMI $<18.5$ ), normal weight $(\mathrm{BMI}=18.5$ to 24.5$)$, overweight $(\mathrm{BMI}=25$ to 29.9$)$ and obese/morbidly obese (BMI $\geq 30$ ), with $2.8 \%, 55.6 \%, 33.3 \%$ and $8.3 \%$ of the cohort in each group, respectively.

The authors found the mortality rate in obese patients to be $24.4 \%$, as compared with $16.6 \%$ in the normal group, although this difference was not statistically significant. Logistic regression did, however, show obesity to be an independent predictor of mortality $(\mathrm{OR}=2.52$, $95 \% \mathrm{CI}=1.3$ to 4.9 ). Admission hypotension was most prevalent in the obese cohort, but again this difference was not statistically significant. Obese patients received more total volume of resuscitation fluid, but when corrected for BMI they received relatively less fluid resuscitation per kilogram of body weight. A larger number of the more obese patients died of hemorrhagic shock as compared with normal weight patients, and this was a significant difference $(6.7 \%$ vs. $1.7 \%, P=0.024)$.

This significantly increased risk of death from hemorrhage in the obese cohort is an interesting finding and possibly a result of relative under-resuscitation, which has been described previously [68]. However, whether it is appropriate to correct for body weight when providing resuscitation is unclear, and resuscitative efforts should be tailored to the patient's hemodynamic physiology. Further, these results should be interpreted cautiously as the obese cohort in this study was a relatively small cohort and the mortality rate was also relatively low. Furthermore, the majority of trauma overall in the cohort was due to blunt injury $(>90 \%)$ and this may not be generalizable to all trauma centers or applicable to all trauma cases. While the work by Nelson and colleagues does support previous studies suggesting increased mortality in obese patients $[63,64,69]$, this trend is not consistent throughout the literature $[62,65,66]$ and additional well-designed studies are needed to determine the actual effect of obesity on mortality in trauma.

\section{Survival and neurologic outcomes following pediatric trauma}

Better than expected survival following post-traumatic arrest in pediatric patients

Reported survival rates for out-of-hospital posttraumatic cardiac arrest (OHPTCA) are uniformly poor [70-72]. Guidelines have been published regarding when to withhold resuscitative efforts following OHPTCA [73], yet withholding cardiopulmonary resuscitation, particularly in children, is often a difficult decision. In a 2012 Critical Care article, Zwingmann and colleagues sought to evaluate and compare outcomes following OHPTCA in both adult and pediatric populations [74].

The authors performed a meta-analysis of literature published from 1964 to 2011, including a total of 47 studies with 6,634 total patients for analysis. Of these, 5,391 patients were adult or mixed populations and 1,243 patients were identifiable as $\leq 8$ years of age. Overall mortality in the adult/mixed group was $96.7 \%$, and was $86.4 \%$ in the pediatric group $(P<0.001)$. More specifically, mortality rates in blunt trauma were $96.7 \%$ and $73.8 \%$, respectively $(P<0.001)$, while penetrating mortality rates remained similar at $96.4 \%$ and $97.8 \%$, respectively. The authors also found what appeared to be differential mortality rates between European and US studies, with mortality rates of $94.1 \%$ in the European studies and $96.1 \%$ in the US studies $(P=0.0013)$.

As is the problem with such methodologies, the metaanalysis by Zwingmann and colleagues is based on generally low-quality evidence and analyzes a small set of clinical parameters. However, the findings do summarize the previous literature demonstrating low overall survival rates from OHPTCA. European studies demonstrated a higher survival rate than the US counterpart, possibly a result of the European model often providing prehospital care at the scene by highly trained physicians. While no difference was found in the adult population between penetrating and blunt trauma, a significant survival difference was noted in pediatric patients with blunt OHPTCA. Previous literature has also demonstrated survival benefit in children [72], particularly for blunt trauma [71]. Therefore, as an important conclusion from this publication, 
this population warrants further scrutiny and has implications for current guidelines on terminating resuscitation efforts for OHPTCA.

\section{Low-volume resuscitation may be beneficial in pediatric trauma patients}

Traumatic injury is a leading cause of morbidity and mortality in children worldwide [75] and hemorrhagic shock from blood loss plays a significant role in poor outcomes [76]. Although it seems intuitive to rapidly replace lost volume, studies in adult populations have shown coagulopathy and increased mortality in patients receiving large-volume crystalloid resuscitation [77-80]. Some guidelines still suggest aggressive hospital fluid replacement in pediatric patients with significant injuries and presumed blood loss [81]. However, there is growing evidence that suggests poor outcomes with this approach [82].

In a 2012 article published in Critical Care, Hussmann and colleagues explored the consequences of fluid resuscitation on pediatric trauma patients through a retrospective analysis of data collected in the German TraumaRegister $\mathrm{DGU}^{\circ}$ [83]. Thirty-one severely injured patients $<15$ years old were selected and demographically matched from each of two major groups based on the reception of low-volume resuscitation $(0$ to $500 \mathrm{ml})$ or high-volume resuscitation $(>500 \mathrm{ml})$ with crystalloid and colloid fluids. The authors found an association between high-volume resuscitation and increased mortality (low-volume resuscitation, 19.4\%; high-volume resuscitation, $25.8 \%$ ), although these results were not statistically significant. Increased need for more blood transfusions (low-volume resuscitation, 9.7\%; high-volume resuscitation, 25.8\%), multiple organ failure rates (low-volume resuscitation, 36.7\%; high-volume resuscitation, 41.4\%), and rescue time (low-volume resuscitation, 62 minutes; high-volume resuscitation, 71.5 minutes) for highvolume transfusion were also nonsignificant.

This study by Hussmann and colleagues was hampered by the small number of patients evaluated and the resulting lack of statistical power. However, the results did suggest a trend toward increased mortality and coagulopathy with large-volume resuscitation in pediatric trauma patients, mirroring recent adult data [78-80]. Based on these results, more formalized studies with adequate power should be performed to determine specific guidelines in pediatric resuscitation in the setting of trauma.

\section{Factors predicting hypothermia in trauma}

Hypothermia in trauma is associated with poorer prognosis and increased mortality $[84,85]$. Causes of hypothermia are multifactorial and probably contribute to the acute coagulopathy of trauma [86]. Injury affecting thermoregulation may result from shock, severe head injury [85] and iatrogenic factors, including the administration of resuscitation fluids [87]. Further, environmental factors such as cold exposure may also contribute. In a 2012 study by Lapostolle and colleagues published in Critical Care, the authors attempt to quantify the contribution of various factors to the development of hypothermia in trauma patients receiving prehospital care [88].

Lapostolle and colleagues undertook a prospective observational study in eight French hospital-based EMS systems from January 2004 through November 2007 [88]. All trauma patients $\geq 18$ years of age who received prehospital care and were transported to hospital were included. The primary endpoint was hypothermia on arrival, defined as body temperature $<35^{\circ} \mathrm{C}$ measured tympanically. Of 448 total patients included, $14 \%$ were hypothermic upon arrival at the hospital. Two of the most significant factors associated with hypothermia were the Revised Trauma Score $(\mathrm{OR}=1.68,95 \% \mathrm{CI}=$ 1.29 to 2.20$)$ and ETI $(\mathrm{OR}=4.23,95 \% \mathrm{CI}=1.61$ to 11.02 ), with $50 \%$ of the hypothermic group intubated as compared with $7 \%$ of euthermic patients. However, these markers may be surrogate variables for a sicker population with increased baseline mortality risk.

Cooler air temperature $\left(11.5^{\circ} \mathrm{C}\right.$ vs. $\left.17.9^{\circ} \mathrm{C}, P<0.0001\right)$ and ground temperature $\left(11.4^{\circ} \mathrm{C}\right.$ vs. $\left.18.1^{\circ} \mathrm{C}, P<0.0001\right)$ were associated with more hypothermia, as were patients found on the ground ( $80 \%$ vs. $56 \%, P<0.01$ ) or found in wet conditions $(22 \%$ vs. $9 \%, P<0.01)$. Colder temperatures of resuscitation fluids $\left(19.5^{\circ} \mathrm{C}\right.$ vs. $22.0^{\circ} \mathrm{C}, P$ $<0.0001)$ and longer scene times $(65$ minutes vs. $60 \mathrm{mi}-$ nutes, $P<0.01)$ were also associated with more cases of hypothermia.

As demonstrated by Lapostolle and colleagues in this paper, the various factors contributing to hypothermia in trauma patients are multifactorial. This work provides some enhanced guidance for prevention, particularly in terms of diminishing risk in the prehospital arena. These include efforts to decrease the scene time, protecting patients from environmental exposures, and keeping patients clothed when possible. Resuscitation fluids should be temperature controlled, as should the internal temperature of the ambulance unit.

\section{Conclusions}

In articles published in Critical Care in 2012, prehospital resuscitation from trauma and cardiac arrest were of particular interest. Prehospital ETI may have improved success rates when utilizing RSI intubation, particularly in experienced providers. The use of a LDB device for CPR may have some benefit in the prehospital arena and this benefit may extend to the ED setting, although further high-quality studies are needed. With regard to patient transport decisions, transport of patients resuscitated from OHCA to a PCI-capable center may be beneficial. Additionally, air 
medical transport of blunt trauma patients was shown to lead to improved outcomes, although this may be due in part to aggressive prehospital interventions.

The need for MT was evaluated using several prediction models. Of these models, the TASH and PWH scores performed the best, although all models are limited and future models using more advanced parameters need to be developed. Obese patients were shown to have increased mortality from hemorrhage, possibly a result of under-resuscitation. However, there is still much debate around this topic and further well-designed evaluations are needed. Factors surrounding the etiology of hypothermia in trauma patients were also examined and found to be multifactorial.

In the pediatric population, biphasic defibrillators have again been demonstrated to have similar outcome profiles to monophasic defibrillators. In line with previous studies conducted in adult populations, large-volume resuscitation may be detrimental in the pediatric population. Additionally, a large meta-analysis demonstrated better than expected survival from OHPTCA, suggesting the need for a re-evaluation of current guidelines for field termination of resuscitative efforts in this population.

\begin{abstract}
Abbreviations
BMI: Body mass index; CPC: Cerebral performance category;

CPR: Cardiopulmonary resuscitation; ED: Emergency department;

EMS: Emergency medical services; ETI: Endotracheal intubation; IH: Induced hypothermia; LDB: Load-distributing band; MT: Massive transfusion; OHCA: Out-of-hospital cardiac arrest; OHPTCA: Out-of-hospital post-traumatic cardiac arrest; OR: Odds ratio; PCl: Percutaneous cardiac intervention; PWH: Prince of Wales Hospital/Rainer; RSI: Rapid sequence induction; TASH: Trauma-associated severe hemorrhage; VF: Ventricular fibrillation; VT: Ventricular tachycardia.
\end{abstract}

\section{Competing interests}

The authors declare that they have no competing interests.

\section{Published: 22 Nov 2013}

\section{References}

1. Anderson ID, Woodford M, de Dombal FT, Irving M: Retrospective study of 1000 deaths from injury in England and Wales. BMJ 1988, 296:1305-1308.

2. Esposito TJ, Sanddal ND, Hansen JD, Reynolds S: Analysis of preventable trauma deaths and inappropriate trauma care in a rural state. J Trauma 1995, 39:955-962.

3. Bernard SA, Nguyen V, Cameron P, Masci K, Fitzgerald M, Cooper DJ, Walker T, Std BP, Myles P, Murray L, Taylor D, Smith K, Patrick I, Edington J, Bacon A, Rosenfeld JV, Judson R: Prehospital rapid sequence intubation improves functional outcome for patients with severe traumatic brain injury: a randomized controlled trial. Ann Surg 2010, 252:959-965.

4. Cobas MA, De la Pena MA, Manning R, Candiotti K, Varon AJ: Prehospital intubations and mortality: a level 1 trauma center perspective. Anesth Analg 2009, 109:489-493.

5. Blostein PA, Koestner AJ, Hoak S: Failed rapid sequence intubation in trauma patients: esophageal tracheal combitube is a useful adjunct. $J$ Trauma 1998, 44:534-537.

6. Dunham CM, Barraco RD, Clark DE, Daley BJ, Davis FE, Gibbs MA, Knuth T, Letarte PB, Luchette FA, Omert L, Weireter L, Wiles CE, EAST Practice Management Guidelines Work Group: Guidelines for emergency tracheal intubation immediately after traumatic injury. J Trauma 2003, 55:162-179.
7. Jensen AG, Callesen T, Hagemo JS, Hreinsson K, Lund V, Nordmark J: Scandinavian clinical practice guidelines on general anaesthesia for emergency situations. Acta Anaesthesio/ Scand 2010, 54:922-950.

8. Lossius HM, Røislien J, Lockey DJ: Patient safety in pre-hospital emergency tracheal intubation: a comprehensive meta-analysis of the intubation success rates of EMS providers. Crit Care 2012, 16:R24

9. Curka PA, Pepe PE, Ginger VF, Ivy MV, Sherrard RC, Zachariah BS: Emergency medical services priority dispatch. Ann Emerg Med 1993, 22:1688-1695

10. Lippmann MJ, Salazar GA, Pepe PE: Prehospital resuscitative interventions: elemental or detrimental? In 2012 Yearbook of Intensive Care and Emergency Medicine. Edited by Vincent JL. Berlin: Springer-Verlag; 2012:483492.

11. Link MS, Atkins DL, Passman RS, Halperin HR, Samson RA, White RD, Cudnik MT, Berg MD, Kudenchuk PJ, Kerber RE: Part 6: electrical therapies: automated external defibrillators, defibrillation, cardioversion, and pacing: 2010 American Heart Association Guidelines for Cardiopulmonary Resuscitation and Emergency Cardiovascular Care. Circulation 2010, 122:S706-S719.

12. Deakin CD, Nolan JP, Sunde K, Koster RW: European Resuscitation Council Guidelines for Resuscitation 2010 Section 3. Electrical therapies: automated external defibrillators, defibrillation, cardioversion and pacing. Resuscitation 2010, 81:1293-1304.

13. Schneider T, Martens PR, Paschen H, Kuisma M, Wolcke B, Gliner BE, Russell $J K$, Weaver WD, Bossaert L, Chamberlain D: Multicenter, randomized, controlled trial of 150-J biphasic shocks compared with 200- to 360-J monophasic shocks in the resuscitation of out-of-hospital cardiac arrest victims. Optimized Response to Cardiac Arrest (ORCA) Investigators. Circulation 2000, 102:1780-1787.

14. White RD, Hankins DG, Atkinson EJ: Patient outcomes following defibrillation with a low energy biphasic truncated exponential waveform in out-of-hospital cardiac arrest. Resuscitation 2001, 49:9-14.

15. Martens PR, Russell JK, Wolcke B, Paschen H, Kuisma M, Gliner BE, Weaver WD, Bossaert L, Chamberlain D, Schneider T: Optimal Response to Cardiac Arrest study: defibrillation waveform effects. Resuscitation 2001, 49:233-243.

16. van Alem AP, Chapman FW, Lank P, Hart AA, Koster RW: A prospective, randomised and blinded comparison of first shock success of monophasic and biphasic waveforms in out-of-hospital cardiac arrest. Resuscitation 2003, 58:17-24.

17. Stothert JC, Hatcher TS, Gupton CL, Love JE, Brewer JE: Rectilinear biphasic waveform defibrillation of out-of-hospital cardiac arrest. Prehosp Emerg Care 2004, 8:388-392.

18. Kudenchuk PJ, Cobb LA, Copass MK, Olsufka M, Maynard C, Nichol G: Transthoracic incremental monophasic versus biphasic defibrillation by emergency responders (TIMBER): a randomized comparison of monophasic with biphasic waveform ascending energy defibrillation for the resuscitation of out-of-hospital cardiac arrest due to ventricular fibrillation. Circulation 2006, 114:2010-2018.

19. Hess EP, Atkinson EJ, White RD: Increased prevalence of sustained return of spontaneous circulation following transition to biphasic waveform defibrillation. Resuscitation 2008, 77:39-45.

20. Tanabe S, Yasunaga H, Koike S, Akahane M, Ogawa T, Horiguchi H, Hatanaka T, Yokota H, Imamura T: Monophasic versus biphasic defibrillation for pediatric out-of-hospital cardiac arrest patients: a nationwide population-based study in Japan. Crit Care 2012, 16:R219.

21. Hock Ong ME, Fook-Chong S, Annathurai A, Ang SH, Tiah L, Yong KL, Koh ZX, Yap S, Sultana P: Improved neurologically intact survival with the use of an automated, load-distributing band chest compression device for cardiac arrest presenting to the emergency department. Crit Care 2012, 16:R144.

22. Christenson J, Andrusiek D, Everson-Stewart S, Kudenchuk P, Hostler D, Powell J, Callaway CW, Bishop D, Vaillancourt C, Davis D, Aufderheide TP, Idris A, Stouffer JA, Stiell I, Berg R, Resuscitation Outcomes Consortium Investigators: Chest compression fraction determines survival in patients with out-of-hospital ventricular fibrillation. Circulation 2009, 120:1241-1247.

23. Bobrow BJ, Clark LL, Ewy GA, Chikani V, Sanders AB, Berg RA, Richman PB, Kern KB: Minimally interrupted cardiac resuscitation by emergency medical services for out-of-hospital cardiac arrest. JAMA 2008, 299:1158-1165. 
24. Berg RA, Hemphill R, Abella BS, Aufderheide TP, Cave DM, Hazinski MF, Lerner EB, Rea TD, Sayre MR, Swor RA: Part 5: adult basic life support: 2010 American Heart Association guidelines for cardiopulmonary resuscitation and emergency cardiovascular care. Circulation 2010, 122:S685-S705.

25. Travers AH, Rea TD, Bobrow BJ, Edelson DP, Berg RA, Sayre MR, Berg MD, Chameides L, O'Connor RE, Swor RA: Part 4: CPR overview: 2010 American Heart Association guidelines for cardiopulmonary resuscitation and emergency cardiovascular care. Circulation 2010, 122:S676-S684.

26. Idris AH, Guffey D, Aufderheide TP, Brown S, Morrison LJ, Nichols P, Powell J, Daya M, Bigham BL, Atkins DL, Berg R, Davis D, Stiell I, Sopko G, Nichol G, Resuscitation Outcomes Consortium (ROC) Investigators: Relationship between chest compression rates and outcomes from cardiac arrest. Circulation 2012, 125:3004-3012.

27. Ong ME, Ornato JP, Edwards DP, Dhindsa HS, Best AM, Ines CS, Hickey S, Clark B, Williams DC, Powell RG, Overton JL, Peberdy MA: Use of an automated, load-distributing band chest compression device for out-ofhospital cardiac arrest resuscitation. JAMA 2006, 295:2629-2637.

28. Hallstrom A, Rea TD, Sayre MR, Christenson J, Anton AR, Mosesso VN Jr, Van Ottingham L, Olsufka M, Pennington S, White L, Yahn S, Husar J, Morris MF، Cobb LA: Manual chest compression vs use of an automated chest compression device during resuscitation following out-of-hospital cardiac arrest: a randomized trial. JAMA 2006, 295:2620-2628.

29. Sasson C, Rogers MA, Dahl J, Kellermann AL: Predictors of survival from out-of-hospital cardiac arrest: a systematic review and meta-analysis. Circ Cardiovasc Qual Outcomes 2010, 3:63-81.

30. Cave DM, Gazmuri RJ, Otto CW, Nadkarni VM, Cheng A, Brooks SC, Daya M, Sutton RM, Branson R, Hazinski MF: Part 7: CPR techniques and devices: 2010 American Heart Association guidelines for cardiopulmonary resuscitation and emergency cardiovascular care. Circulation 2010, 122:S720-S728.

31. Herlitz J, Bang A, Gunnarsson J, Engdahl J, Karlson BW, Lindqvist J, Waagstein L: Factors associated with survival to hospital discharge among patients hospitalised alive after out of hospital cardiac arrest: change in outcome over 20 years in the community of Goteborg, Sweden. Heart 2003, 89:25-30.

32. Nichol G, Thomas E, Callaway CW, Hedges J, Powell JL, Aufderheide TP, Rea T, Lowe R, Brown T, Dreyer J, Davis D, Idris A, Stiell I: Regional variation in out-of-hospital cardiac arrest incidence and outcome. JAMA 2008, 300:1423-1431.

33. Berdowski J, Berg RA, Tijssen JG, Koster RW: Global incidences of out-ofhospital cardiac arrest and survival rates: systematic review of 67 prospective studies. Resuscitation 2010, 81:1479-1487.

34. Atwood C, Eisenberg MS, Herlitz J, Rea TD: Incidence of EMS-treated outof-hospital cardiac arrest in Europe. Resuscitation 2005, 67:75-80.

35. Bernard SA, Gray TW, Buist MD, Jones BM, Silvester W, Gutteridge G, Smith $\mathrm{K}$ : Treatment of comatose survivors of out-of-hospital cardiac arrest with induced hypothermia. N Engl J Med 2002, 346:557-563.

36. The Hypothermia after Cardiac Arrest Study Group: Mild therapeutic hypothermia to improve the neurologic outcome after cardiac arrest. $N$ Engl J Med 2002, 346:549-556.

37. Bendz B, Eritsland J, Nakstad AR, Brekke M, Klow NE, Steen PA, Mangschau A: Long-term prognosis after out-of-hospital cardiac arrest and primary percutaneous coronary intervention. Resuscitation 2004, 63:49-53.

38. Sunde K, Pytte M, Jacobsen D, Mangschau A, Jensen LP, Smedsrud C, Draegni T, Steen PA: Implementation of a standardised treatment protocol for post resuscitation care after out-of-hospital cardiac arrest. Resuscitation 2007, 73:29-39.

39. Stub D, Smith K, Bray JE, Bernard S, Duffy SJ, Kaye DM: Hospital characteristics are associated with patient outcomes following out-of-hospital cardiac arrest. Heart 2011, 97:1489-1494.

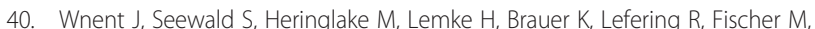
Jantzen T, Bein B, Messelken M, Gräsner JT: Choice of hospital after out-of-hospital cardiac arrest - a decision with far-reaching consequences: a study in a large German city. Crit Care 2012, 16:R164.

41. MacKenzie EJ, Rivara FP, Jurkovich GJ, Nathens AB, Frey KP, Egleston BL, Salkever DS, Scharfstein DO: A national evaluation of the effect of traumacenter care on mortality. N Engl J Med 2006, 354:366-378.

42. Bledsoe BE, Wesley AK, Eckstein M, Dunn TM, O'Keefe MF: Helicopter scene transport of trauma patients with nonlife-threatening injuries: a metaanalysis. J Trauma 2006, 60:1257-1265.
43. Brown JB, Stassen NA, Bankey PE, Sangosanya AT, Cheng JD, Gestring ML: Helicopters and the civilian trauma system: national utilization patterns demonstrate improved outcomes after traumatic injury. J Trauma 2010, 69:1030-1034

44. Sullivent EE, Faul M, Wald MM: Reduced mortality in injured adults transported by helicopter emergency medical services. Prehosp Emerg Care 2011, 15:295-302.

45. Galvagno SM Jr, Haut ER, Zafar SN, Millin MG, Efron DT, Koenig GJ Jr, Baker SP, Bowman SM, Pronovost PJ, Haider AH: Association between helicopter vs ground emergency medical services and survival for adults with major trauma. JAMA 2012, 307:1602-1610.

46. Desmettre $T$, Yeguiayan JM, Coadou H, Jacquot C, Raux M, Vivien B, Martin C, Bonithon-Kopp C, Freysz M, French Intensive Care Recorded in Severe Trauma: Impact of emergency medical helicopter transport directly to a university hospital trauma center on mortality of severe blunt trauma patients until discharge. Crit Care 2012, 16:R170.

47. Stiell IG, Nesbitt LP, Pickett W, Munkley D, Spaite DW, Banek J, Field B, Luinstra-Toohey L, Maloney J, Dreyer J, Lyver M, Campeau T, Wells GA, OPALS Study Group: The OPALS Major Trauma Study: impact of advanced life-support on survival and morbidity. CMAJ 2008, 178:1141-1152.

48. Brohi K, Singh J, Heron M, Coats T: Acute traumatic coagulopathy. J Trauma 2003, 54:1127-1130.

49. Davenport R, Curry N, Manson J, De'Ath H, Coates A, Rourke C, Pearse R, Stanworth S, Brohi K: Hemostatic effects of fresh frozen plasma may be maximal at red cell ratios of 1:2. J Trauma 2011, 70:90-95.

50. Cotton BA, Au BK, Nunez TC, Gunter OL, Robertson AM, Young PP: Predefined massive transfusion protocols are associated with a reduction in organ failure and post injury complications. J Trauma 2009, 66:41-48.

51. Dente CJ, Shaz BH, Nicholas JM, Harris RS, Wyrzykowski AD, Patel S, Shah A, Vercruysse GA, Feliciano DV, Rozycki GS, Salomone JP, Ingram WL: Improvements in early mortality and coagulopathy are sustained better in patients with blunt trauma after institution of a massive transfusion protocol in a civilian level I trauma center. J Trauma 2009, 66:1616-1624.

52. Davenport R, Manson J, De'Ath H, Platton S, Coates A, Allard S, Hart D, Pearse R, Pasi KJ, MacCallum P, Stanworth S, Brohi K: Functional definition and characterization of acute traumatic coagulopathy. Crit Care Med 2011, 39:2652-2658.

53. Cotton BA, Faz G, Hatch QM, Radwan ZA, Podbielski J, Wade C, Kozar RA, Holcomb JB: Rapid thromboelastography delivers real-time results that predict transfusion within 1 hour of admission. J Trauma 2011, 71:407-414.

54. Brockamp T, Nienaber U, Mutschler M, Wafaisade A, Peiniger S, Lefering R, Bouillon B, Maegele M, TraumaRegister DGU: Predicting on-going hemorrhage and transfusion requirement after severe trauma: a validation of six scoring systems and algorithms on the TraumaRegister DGU. Crit Care 2012, 16:R129.

55. Yücel N, Lefering $R$, Maegele M, Vorweg M, Tjardes T, Ruchholtz S, Neugebauer EA, Wappler F, Bouillon B, Rixen D, Polytrauma Study Group of the German Trauma Society: Trauma Associated Severe Hemorrhage (TASH)-Score: probability of mass transfusion as surrogate for life threatening hemorrhage after multiple trauma. J Trauma 2006, 60:1228-1236.

56. Rainer TH, Ho AM, Yeung JH, Cheung NK, Wong RS, Tang N, Ng SK, Wong GK, Lai PB, Graham CA: Early risk stratification of patients with major trauma requiring massive blood transfusion. Resuscitation 2011, 82:724-729.

57. Vandromme MJ, Griffin RL, McGwin G Jr, Weinberg JA, Rue LW 3rd, Kerby JD: Prospective identification of patients at risk for massive transfusion: an imprecise endeavor. Am Surg 2011, 77:155-161.

58. Nunez TC, Voskresensky IV, Dossett LA, Shinall R, Dutton WD, Cotton $B A$ : Early prediction of massive transfusion in trauma: simple as ABC (assessment of blood consumption)? J Trauma 2009, 66:346-352.

59. Schreiber MA, Perkins J, Kiraly L, Underwood S, Wade C, Holcomb JB: Early predictors of massive transfusion in combat casualties. J Am Coll Surg 2007, 205:541-545.

60. Larson CR, White CE, Spinella PC, Jones JA, Holcomb JB, Blackbourne LH, Wade CE: Association of shock, coagulopathy, and initial vital signs with massive transfusion in combat casualties. J Trauma 2010, 69:S26-S32. 
61. World Health Organization: Obesity: Preventing and Managing the Global Epidemic. Report of a WHO Consultation, WHO Technical Report Series 894. Geneva: World Health Organization; 2000.

62. Ciesla DJ, Moore EE, Johnson JL, Burch JM, Cothren CC, Sauaia A: Obesity increases risk of organ failure after severe trauma. J Am Coll Surg 2006, 203:539-545.

63. Byrnes MC, McDaniel MD, Moore MB, Helmer SD, Smith RS: The effect of obesity on outcomes among injured patients. J Trauma 2005, 58:232-237.

64. Neville AL, Brown CV, Weng J, Demetriades D, Velmahos GC: Obesity is an independent risk factor of mortality in severely injured blunt trauma patients. Arch Surg 2004, 139:983-987.

65. Newell MA, Bard MR, Goettler CE, Toschlog EA, Schenarts PJ, Sagraves SG, Holbert D, Pories WJ, Rotondo MF: Body mass index and outcomes in critically injured blunt trauma patients: weighing the impact. J Am Coll Surg 2007, 204:1056-1061.

66. Duane TM, Dechert T, Aboutanos MB, Malhotra AK, Ivatury RR: Obesity and outcomes after blunt trauma. J Trauma 2006, 61:1218-1221.

67. Nelson J, Billeter AT, Seifert B, Neuhaus V, Trentz O, Hofer CK, Turina M: Obese trauma patients are at increased risk of early hypovolemic shock: a retrospective cohort analysis of 1,084 severely injured patients. Crit Care 2012, 16:R77

68. Winfield RD, Delano MJ, Lottenberg L, Cendan JC, Moldawer LL, Maier RV, Cuschieri J: Traditional resuscitative practices fail to resolve metabolic acidosis in morbidly obese patients after severe blunt trauma. J Trauma 2010, 68:317-330.

69. Hoffmann M, Lefering R, Gruber-Rathmann M, Rueger JM, Lehmann W, Trauma Registry of the German Society for Trauma Surgery: The impact of BMI on polytrauma outcome. Injury 2012, 43:184-188.

70. Lockey D, Crewdson K, Davies G: Traumatic cardiac arrest: who are the survivors? Ann Emerg Med 2006, 48:240-424.

71. Stockinger ZT, McSwain NE Jr: Additional evidence in support of withholding or terminating cardiopulmonary resuscitation for trauma patients in the field. J Am Coll Surg 2004, 198:227-231.

72. Atkins DL, Everson-Stewart S, Sears GK, Daya M, Osmond MH, Warden CR, Berg RA, Resuscitation Outcomes Consortium Investigators: Epidemiology and outcomes from out-of-hospital cardiac arrest in children: the Resuscitation Outcomes Consortium Epistry-Cardiac Arrest. Circulation 2009, 119:1484-1491.

73. Hopson LR, Hirsh E, Delgado J, Domeier RM, McSwain NE Jr, Krohmer J, National Association of EMS Physicians Standards and Clinical Practice Committee; American College of Surgeons Committee on Trauma: Guidelines for withholding or termination of resuscitation in prehospital traumatic cardiopulmonary arrest: a joint position paper from the National Association of EMS Physicians Standards and Clinical Practice Committee and the American College of Surgeons Committee on Trauma. Prehosp Emerg Care 2003, 7:141-146.

74. Zwingmann J, Mehlhorn AT, Hammer T, Bayer J, Südkamp NP, Strohm PC: Survival and neurologic outcome after traumatic out-of-hospital cardiopulmonary arrest in a pediatric and adult population: a systematic review. Crit Care 2012, 16:R117.

75. Statter M, Schuble T, Harris-Rosado M, Liu D, Quinlan K: Targeting pediatric pedestrian injury prevention efforts: teasing the information through spatial analysis. J Trauma 2011, 71:511-516.

76. Kauvar DS, Wade CE: The epidemiology and modern management of traumatic hemorrhage: US and international perspectives. Crit Care 2005, 9:1-9.

77. Bickell WH, Wall MJ, Pepe PE, Martin RR, Ginger VF, Allen MK, Mattox KL: Immediate versus delayed fluid resuscitation for hypotensive patients with penetrating torso injury. N Engl J Med 1994, 331:1105-1109.

78. Hussmann B, Lefering R, Waydhas C, Touma A, Kauther MD, Ruchholtz S, Lendemans S, Trauma Registry of the German Society for Trauma Surgery: Does increased prehospital replacement volume lead to a poor clinical course and an increased mortality? A matched-pair analysis of 1896 patients of the Trauma Registry of the German Society for Trauma Surgery who were managed by an emergency doctor at the accident site. Injury 2013, 44:611-617.

79. Haut ER, Kalish BT, Cotton BA, Efron DT, Haider AH, Stevens KA, Kieninger AN, Cornwell EE, Chang DC: Prehospital intravenous fluid administration is associated with higher mortality in trauma patients: a National Trauma Data Bank analysis. Ann Surg 2011, 253:371-377.
80. Rourke C, Curry N, Khan S, Taylor R, Raza I, Davenport R, Stanworth S, Brohi K: Fibrinogen levels during trauma hemorrhage, response to replacement therapy, and association with patient outcomes. J Thromb Haemost 2012, 10:1342-1351.

81. Schweer L: Pediatric trauma resuscitation: initial fluid management. J Infus Nurs 2008, 31:104-111.

82. Morrell BJ, Vinden C, Singh RN, Kornecki A, Fraser DD: Secondary abdominal compartment syndrome in a case of pediatric trauma shock resuscitation. Pediatr Crit Care Med 2007, 8:67-70.

83. Hussmann B, Lefering R, Kauther MD, Ruchholtz S, Moldzio P, Lendemans S, TraumaRegister DGU ${ }^{\otimes}$ : Influence of prehospital volume replacement on outcome in polytraumatized children. Crit Care 2012, 16:R201.

84. Wang HE, Callaway CW, Peitzman AB, Tisherman SA: Admission hypothermia and outcome after major trauma. Crit Care Med 2005, 33:1296-1301.

85. Rubiano AM, Sanchez Al, Estebanez G, Peitzman A, Sperry J, Puyana JC: The effect of admission spontaneous hypothermia on patients with severe traumatic brain injury. Injury 2013, 44:1219-1225.

86. Hess JR, Brohi K, Dutton RP, Hauser CJ, Holcomb JB, Kluger $Y$, Mackway-Jones K, Parr MJ, Rizoli SB, Yukioka T, Hoyt DB, Bouillon B: The coagulopathy of trauma: a review of mechanisms. J Trauma 2008, 65:748-754.

87. Bukur M, Hadjibashi AA, Ley EJ, Malinoski D, Singer M, Barmparas G, Margulies D, Salim A: Impact of prehospital hypothermia on transfusion requirements and outcomes. J Trauma Acute Care Surg 2012, 73:1195-1201.

88. Lapostolle F, Sebbah JL, Couvreur J, Koch FX, Savary D, Tazarourte K, Egman G, Mzabi L, Galinski M, Adnet F: Risk factors for onset of hypothermia in trauma victims: the HypoTraum study. Crit Care 2012, 16:R142.

\section{$10.1186 /$ cc13128}

Cite this article as: Goldberg et al:: Year in review 2012: Critical Care out-of-hospital cardiac arrest and trauma. Critical Care 2013, 17:248 